\title{
Macroergonomics in Air Traffic Control - The Approach of a New System
}

\author{
Luiza Helena Boueri Rebello \\ Universidade Federal Fluminense - UFF, Escola de Engenharia, TDT, Desenho Industrial \\ Rua Passos da Pátria 156, Bloco D, São Domingos, Niterói - RJ, 24210-240, Brazil \\ lunarebello@globo.com
}

\begin{abstract}
This paper aims to make a presentation of a study in order to obtain solutions for a better adequacy of a complex production system, where the system of air traffic control, and the Brazilian system that is in phase of modifications to a human-machine relationships over the working procedures in the light of the constant innovations in information systems in order to improve flight safety.
\end{abstract}

Keywords: Macroergonomics, Air Traffic Control, Flight Safety.

\section{Introduction}

When an air travel is made, both the crew as the passengers of the aircraft depend on a full and secure integration with a series of systems that range from the crew training, passing by the manufacturer of the aircraft and its maintenance, until the air traffic control systems, that will administer the landing, takeoff procedures and aircraft navigation.

With globalization started in the early 1990s, there was a growth of air traffic volume growth in the volume of cargo and transport of people. Reflecting this growth came the need to increase the system of air traffic control through a management, which became a fundamental element to ensure the safety of flights.

This article aims to make a presentation of a study that in order to obtain solutions for a better adequacy of a complex production system, where the system of air traffic control, which is still under development and readjustment thus human-machine relationships over the working procedures in the light of the constant innovations in information systems. This approach is in macroergonomics procedures.

\section{The Problems}

The Brazilian air accidents involving the Gol flights 1907 occurred on September 29th 2006 and TAM 3054 occurred on July 17th 2007, brought to light various problems related to the Brazilian airline industry. The first accident caused the death of 154 people and led to the crisis, that at the time was called popularly air "blackout" which originated a CPI - Parliamentary Committee of Inquiry - Crisis of Air Traffic 
System [1]. In July 2007, when the crisis seemed to be solved, a new accident occurred, the flight 3054 TAM in Congonhas airport in São Paulo, causing the death of 199 people. The crisis broke, forcing the ANAC - National Civil Aviation Agency to take an urgent action [2].

The bad administration of the Brazilian civil aviation that occurred in the recent past managerial interference caused that could truncate information of control organization (tower-TWR/approach-APP/area control-ACC). Example: in the line of direct connection to the area control centre (ACC) of Brasilia did not work for 2 hours, causing a major problem of communication and hogging all the controllers of this jurisdiction area control centre, causing an "air" blackout and chaos in various Brazilian airports.

In accordance with air traffic control, the problems will not be solved by reviewing only the design of workstations and action procedures. We must, above all, review issues relating to the work organization and the work product itself as a whole.

According to Hendrick/Kleiner [3], conceptually, the macroergonomics is a topdown approach for sociotechnical systems, system design and implementation of the global system work project for human interfaces projects work, human-machine and human-software. However, in practice, it is much more comprehensive and consists of a general analysis and structuring of the general system. So, macroergonomics deals with the human-organization interface, which is the most comprehensive levels (macro) to more specific and restricted levels of a problem (micro).

In this case, this interface must ensure the quality of human work next to the control systems, air traffic from the job controller until the organization to increase safety decision-making, thereby, the total safety of flights and the control of flow of aircrafts.

With the CPI of the air "blackout" [1], many questions appears concerning the existing control system. Then, a new system of air traffic control was created to increase the safety and effectiveness. This system was created by ATECH - Fundação de Aplicações de Tecnologias Críticas by looking at the real need of controllers towards the increasing technological innovation in air traffic control systems in the world.

Not that the previous system of radar data handling and flight plans, called ESCA4000 , was bad, but there were flaws in the system software that created insecurity in some control procedures, which is unacceptable when it comes to the issue of flight safety.

\section{Hypotheses}

At work in air traffic control, human error is a frequent occurrence of accidents and incidents. Common failures and is involved in systems. Only in the USA in 1996 there were about 12 thousand failures during control procedures caused by obsolete equipment. According to this large number of failures, a system was created by the MITRE Corporation for the Federal Aviation Administration (FAA) [4], called URET - User Request Evaluation Tool, which provided an increase in the safety of flights, in $30 \%$ the capacity of the aircraft and airports receive reduced by $20 \%$ the 
submersion landings and delays. URET prototype is being tested in ACC (area control centre) of Memphis and Indianapolis since 1998 and is still in the stage of implementation for other control centres of USA.

The primary function of URET is to help the drivers to administer the arrival of aircrafts and maintain a secure flow of traffic, because the system indicates the runway should be used and the arrival of the aircraft. [5]

In European terms EUROCONTROL - European Organization for the Safety of Air Navigation, is an organization that aims to develop a system of uniform air traffic control, integrated, secure and proposes considering ergonomics through direct work with human-computer interface and interface controller. It is one of the institutions that have defined interface standards and thus increasingly industry has embraced these converging standards for a common interface operation regardless of manufacturer. [6]

In Brazil, the recent lack of reliability in the system of air traffic control was crucial due to maladministration of Brazilian Civil Aviation and conflicting information could generate interference or inadequate control bodies (TWR/APP/ACC).

The ESCA-4000 was implemented in the mid-1990s and in less than 20 years a new change is occurring on the systems of air traffic control in Brazil, with a new Brazilian system, designed by ATECH, called SAGITARIO, which will replace the system ESCA-4000. Not deploy a new system of capture and receiving information via radar scope and database with cutting-edge technology, if the radar antenna systems and radio-telephony are not reliable. [7]

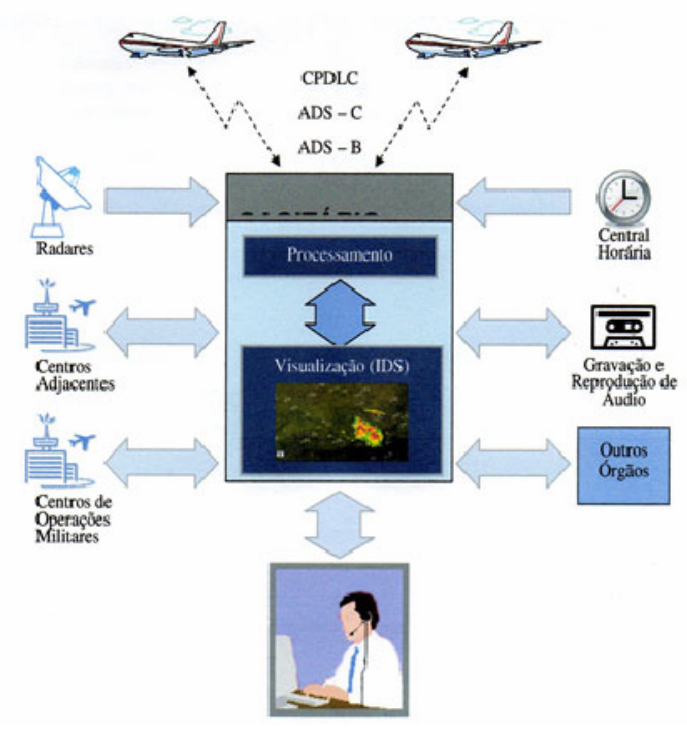

Fig. 1. SVTD overview

The software of air traffic control treatment system and data visualization (STVD), developed and maintained by ATECH Foundation, will be deployed in multiple approximation control centres (APP) and the area control center (ACC) in Brazil, 
Brasilia APP that is responsible for control of 600 daily flights, which started operation in May 2009. Figure 1 shows an overview of SVTD, the various components that make up the system and the communication between these components [8].

The APP is responsible for controlling the aircraft traffic and phases of an airport runway. The solution developed by ATECH for the APP is already present in the APPs of São Paulo (SP), Rio de Janeiro (RJ), Belo Horizonte (MG), Natal (RN), Curitiba (PR), Florianópolis (SC), Recife (EP), Cuiabá (MT), Campo Grande (MS), Belém (PA) and Pirassununga (SP). The forecast is that by 2010, the 22 major centres operating with revitalized systems. The program of modernization of the APP is part of an initiative of the Brazilian Air Force.

In this system, human-computer interface is one of the main components of the system, noting the importance of the connection between the controller and the transmissions of air-earth messages.

Second Endo et alii [8], SAGITARIO - sub-system of visualization of air situation (IDS) of traffic management system was designed as "air international practices and standards defined by EUROCONTROL to create agile, integrated, interfaces and secure systems for the operation of air traffic management."

The SAGITARIO system has innovations concerning HCI and information architecture. The system was developed by observing the object-oriented programming, not forgetting the sophistication of information treatment when air traffic control, whether or not with graphical information.

With this new system is there a significant change in imaging of flight plans. The ESCA-4000, electronic flight plans were a display next to the radar, and the controller was required to interact with at least two interfaces at the same time.

Figure 2 shows a TWR controlling position, with the ESCA-4000 system where the controller has to deal with multi-tasking work.

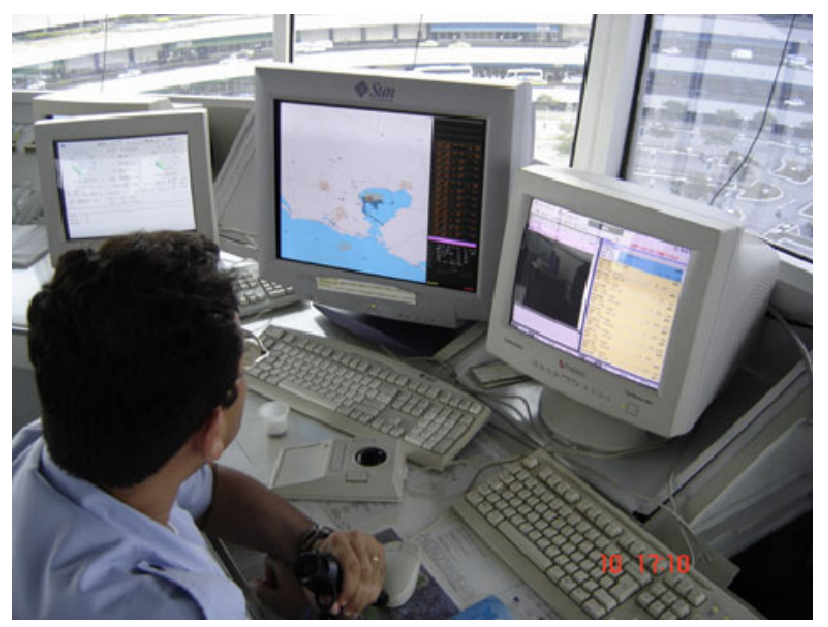

Fig. 2. Workstation with additional display for flight plans (right) 
With the new SAGITARIO system, the flight plan information can be submitted along with the summary information screen of the radar, as the demand for information about the flight that is under control.

In Figure 3, you can view the basic summary screen of the radar.

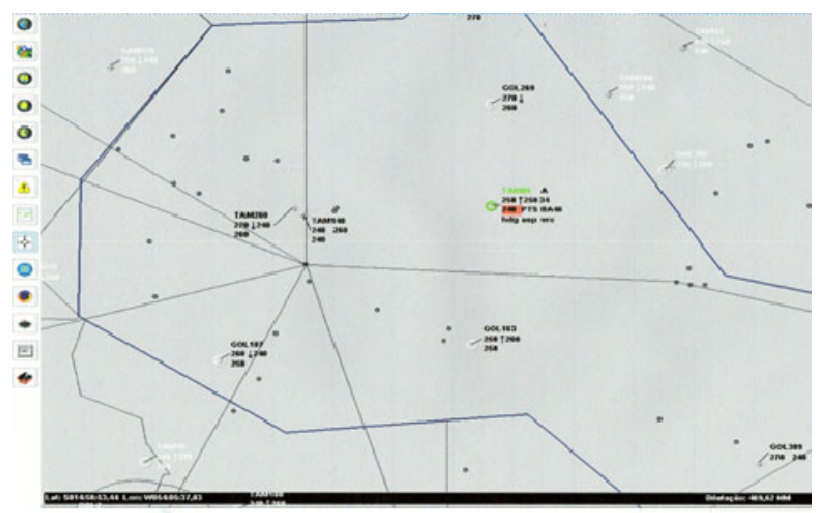

Fig. 3. Basic summary screen

The flight plan will be shown through smart tag, which will show you the basic information from the aircraft identification. When you hover your cursor over the default label, it will show all available information concerning flight (extended label).

In Figure 4.1 and 4.2 shows the new default label and extended label.

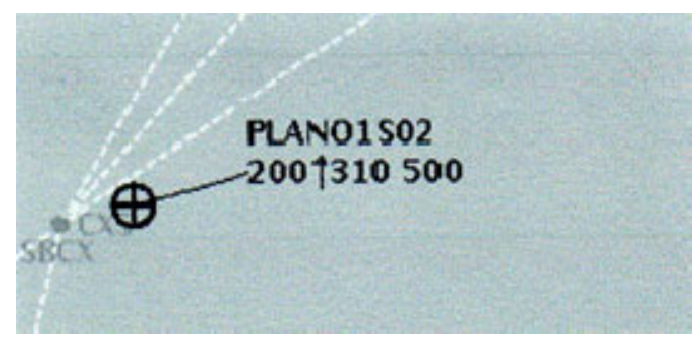

Fig. 4.1. Default label

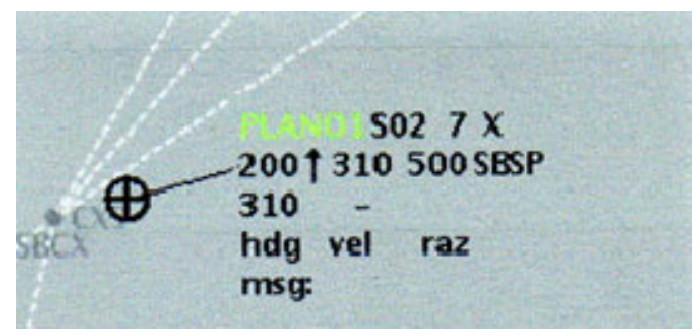

Fig. 4.2. Extended label 
By using the mouse or track ball, the controller may interact directly on an extended label fields through a menu action. It is therefore down efficient information being in one single interface.

In Figure 5 you can see the menu action on the field (speed) of extended label.

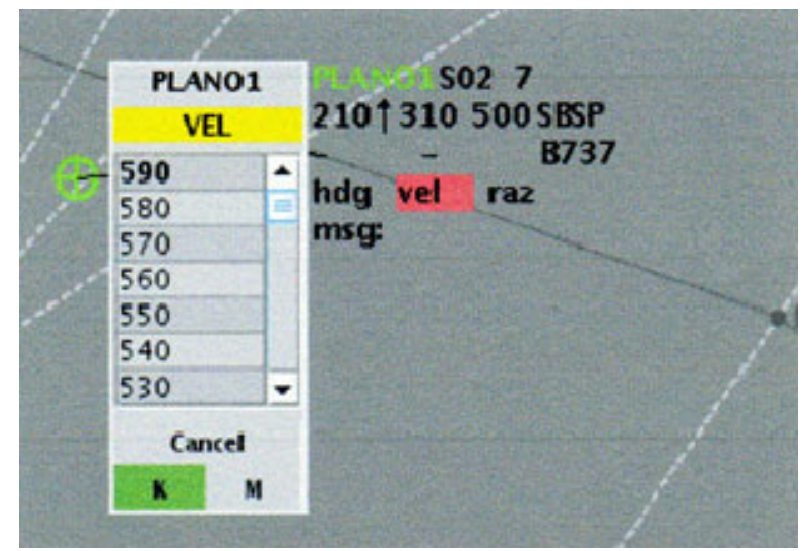

Fig. 5. Example of Action Menu



Fig. 6. Weather information of image of SAGITARIO

This new system you can work with images without the danger of loosing radar information. You can make edits graphics in the flight plan. There is also a toolbar secondary features, which can be closed when not in use to maximize the use of 
monitor area with radar information. If after the fact to have a weather images overlay (as shown in Figure 6), which can be used as another element of support for the decision making of the controller. In contrast, in the previous system, resulting in a weather information to the monitor, forcing the controller to divert your attention from the radar summary screen during the development of its task.

\section{An Effective Method in Macroergonomics}

A survey and analysis of data from the production system as a whole should be done. The method of analysis will be participatory approach (participatory ergonomics).

Participatory ergonomics has been considered the most appropriate approach and more applied within the context of macroergonomics. Participatory ergonomics looks exactly involve multiple organizational levels in the identification, analysis and troubleshooting.

Thus, participatory ergonomics strategy is to encourage participation, because the involvement of employees in resolve ergonomic problems can generate greater trust, interest and experience, to see and solve problems related to your work, often eliminating the presence of specialists.

The participation of individuals involved in the work process, provides ergonomic intervention has better result, taking into account the variability and reliability issues in systems.

This intervention should be made at four levels:

1. Human-Interface: the environmental and environment with the work relationship;

2. Human-Machine Interface: the direct interaction with the system;

3. Human-Information Interface: the issue of information exchange. As it is made. In the case of air traffic control, the issue is crucial for more modern system used, since the information exchange is the central element of any action.

4. Human-Interface: in the organizational aspect, since it is directly related to managing everything that occurs in jobs, work procedures and the organization that may influence on the system.

\subsection{Variability and Reliability in Air Traffic Control}

The workload changes according to the variability and reliability is closely linked to related reactions with the demands of work situations.

According to Vidal/Simoni [9], the concept of variability in work means changing patterns and references to the execution of tasks, this of course referring to in the communication process based on air traffic control.

Methodically, there are forms of variability. They can be differentiated as: technical variability (an equipment failure), work process variability (such as the worker intervenes at work) and the human variability, because people are not different machines and are naturally. The way of an operator to interpret information may be different from another, since they may have different ways of interpreting job content. Ideally, the tasks are structured and adapted to the productive system variants, i.e. the different patterns of variability in order to achieve the system reliability. 
In terms of reliability, the mental workload can influence to decrease reliability, having in mind that the operator has a limitation on the ability of mental processing of information.

There are techniques for increased reliability, which could also be means to mitigate variability. These techniques are the following:

- Terotecnology: anticipation of a situation before there is a real need. Example: the controller can anticipate a procedure on the basis of a radar information.

- Preventive maintenance in its most profound meaning.

- Fault trees: incident relationship with facts that have already occurred. Example: what were the most common accidents/incidents in a terminal and/or route.

- Simulations of various types.

- Mapping: to be done in working conditions to a better understanding of events.

As was discussed earlier, Brazil has gone through a major period of lack of reliability in the system of air traffic control and now is restructuring, if renewing and modernizing to through the use of new technologies where human-computer interface is paramount and, in parallel to the evolution of current systems of new international air management concept of the future, the CNS-ATM (communication, navigation and surveillance air traffic management) that uses flight management features supported in communications satellites for aircraft navigation.

Not deploy a new system of capture and receiving information via radar scope and database with cutting-edge technology, the radio-telephony system and data. Your performance can also degrade more terminals in some handling due to the large amount of noise often interfered.

Fortunately the controllers are already accustomed to these types of noise, and able to work around the problem; but it would be much better if they don't exist to ensure the safety of the information received and transmitted. The solution can be the creation of a system of communication done through optical fibers and have the possibility to block the interference through the use of passwords.

Much of the reliability of the system is related to the speed with which the driver can see the future (trivial task during the vectoring of information for each flight in radar). The new systems, which use assistance per computer, assist in the run-up to avoiding conflicting routes; you must have full knowledge of system activity and that the decision can be made at the right time without doubts and errors.

Since the beginning of training should give value to the content of the task in terms of actual work, if possible, showing the differences and similarities between the old system and the most modern system. It is also important that the controller has the knowledge of the conventional procedure (also called Basic), because such a system can still be used as stand-by in case there are any drop in more modern system. All control centers in the world are still in a conventional intermediate stage and still works as a pro-reliability element, which is natural in situations of transition.

There should be a special training for the control of information together with the transmission of information via voice and typing, which requires a specific skill in terms of specific codes and their applications. These codes fall into an operation according to Falzon [10]. The greater the ease and speed controller type information using the terminology of control, both in the mother tongue as in English, controllers not experience security in the transmission of information even in time stress. 


\section{Participation, Research and Troubleshooting}

Must give due importance to controller activity under the cooperative and participatory work, because in terms of training these characteristics are virtually neglected. In fact they should be highlighted and encouraged where it would consider specific training modules and collective activities. There should be an incentive for an improvement in the training of new controllers. Older controllers, and therefore, are retiring and younger are facing problems in current training because the training process is very fast. If is necessary, a monitoring support for new controllers.

It would also be highly desirable, from the point of view, if there was a planned exchange of information between controllers and pilots, for which there is greater understanding of their work, in order to avoid misunderstandings. In other words, is a representation of mutual activity to provide adequate levels of cooperations. As a result, there is better integration for communications, with guarantee greater flight safety.

Questions about the work of controllers in Brazil should be discussed with operators and supervisors, pilots, by ANAC (National Civil Aviation Agency) and the Ministry of Defense. These discussions are presented in FAA, ICAO and Eurocontrol.

Should prepared questionnaire concerning the actors opinion research this scenario as the work performed. The issues addressed are: degree of satisfaction at the activities, the pace of work environment, degree of difficulty of learning, understanding of information, equipment and systems that is being used, degree of comfort and physical and mental fatigue.

After the research, an analysis should be made to find the mismatch points.

Finally, you will need to develop new procedures are in accordance with international standards. A world of systems standardization is necessary, since the air traffic control is not related only to a particular country, is a global issue.

\section{Conclusion}

This article presented the current situation changes in air traffic control in Brazil, a work in progress, and points out the importance of careful review in the light of macroergonomics to the improvement of the work of controllers, aimed at the total safety of flights along with better fluidity in airspace management and soil at airports.

\section{References}

1. BRASIL - SENADO FEDERAL. Relatório Final - CPI do "Apagão Aéreo". Brasília, p. 2156 (2007)

2. BRASIL - CÂMARA DOS DEPUTADOS. CPI - Comissão Parlamentar de Inquérito Crise do Sistema de Tráfego Aéreo. Brasília, p. 713 (2007)

3. Hendrick, H., Kleiner, B.M.: EVC - Editora Virtual Científica, Rio de Janeiro (2006)

4. MITRE CAADS - URET, http://caasd.org/work/project_details.cfm?item_id=156

5. FAA - URET, http://hf.tc.faa.gov/capabilities/uret.htm

6. EUROCONTROL, http://www. eurocontrol.int 
7. Siedwerdt, E.: O Modelo de Controle do Espaço Aéreo Brasileiro e sua Integração com Outros Sistemas. Apresentação em PowerPoint. VII SITRAER - Simpósio de Transporte Aéreo, Rio de Janeiro (2008)

8. Endo, R., et al.: Interface Humano-Computador do Sub-Sistema de Visualização de Situação Aérea do Sistema de Gerenciamento de Tráfego Aéreo. In: Proceedings do VII SITRAER - Simpósio de Transporte Aéreo, Rio de Janeiro, pp. 576-584 (2008)

9. Vidal, M., de Simoni, M.: Análise da Condição Humana em Situações de Trabalho, Rio de Janeiro, COPPE/UFRJ (1990)

10. Falzon, P.: Ergonomie Cognitive du Dialogue, 1re ed., p. 173. Presses Universitaires de Grenoble, Grenoble (1989) 